\title{
ECC
}

\section{Selective trimethylsilylation of alcohols and phenols with hexamethyldisilazane catalyzed by $\mathrm{LaCoO}_{3}$ perovskite}

\author{
Ebrahim Mehdipour,*, Ehsan Baharloueia, Zohre Zarnegar ${ }^{b}$ \\ a Department of Chemistry, Faculty of Science, Lorestan University, Khorramabad, Iran \\ ${ }^{b}$ Research Affiliate, Department of Chemistry, Payame Noor University, P.O. BOX 19395-4697 \\ Tehran, Iran
}

Received: 28 January 2019, Accepted: 17 March 2019, Published: 1 October 2019

\begin{abstract}
Trimethylsilylation of alcohols and phenols were carried out under solvent-free conditions with hexamethyldisilazane (HMDS) using $\mathrm{LaCoO}_{3}$ perovskite. $\mathrm{LaCoO}_{3}$ as an efficient catalyst accelerated this reaction under milder condition. The advantages of this method are evident regarding, easy separation, low cost and low catalyst loading, lack of pollution, easy work-up, and selective protection of primary and secondary alcohols.
\end{abstract}

Keywords: Protection; trimethylsilylation; trimethylsilyl ether; hxamethyldisilazane; heterogeneous catalyst.

\section{Introduction}

Silyl ethers are the most widely used protecting groups for hydroxyl groups such as alcohols and phenols in the multi-step synthetic organic chemistry [1]. Several methods have been reported for the preparation of silyl ethers using various types of silylating agents [2-5]. 1,1,1,3,3,3hexamethyldisilazane (HMDS), as a stable and inexpensive reagent, is used for the synthesis of silyl ethers. However, the use of HMDS has limitations such as its low silylating power, forceful condition and long reaction times. Therefore, to activate this reagent, an appropriate catalytic system is required [6]. For its efficiency, a variety of catalysts have been used [6-12]. Although these catalytic systems provide an improvement, in most cases, they are characterized by various limitations such as low selectivity, tedious reaction procedure, moisture sensitive, and toxic or expensive of the catalyst [12]. Hence, the development of new procedures to circumvent these problems is still in demand.

In recent years, perovskite-type oxides have been made in the chemical reactions due to their outstanding properties of good thermal stability, high activity, and non-toxicity [13]. Among perovskite-type oxides, the extensive use of $\mathrm{LaCoO}_{3}$ as a catalyst and oxidant reagent is due to many characteristic features such as interesting electrical and electrocatalytic properties, very high electronic conductivity and good ionic conductivity [14]. $\mathrm{LaCoO}_{3}$ presents high catalytic activity in the oxidation of organic compounds [15], the

*Corresponding author: Ebrahim Mehdipour 
production of lactic acid from cellulosic biomass [16], and photocatalytic water oxidation [17].

A number of different analytical methods have been developed for the successful identification of various organic samples. Gas chromatographymass spectrometry (GC-MS) is an analytical technique that combines the features of gas-chromatography and mass spectrometry to identify different substances within a test sample. GC-
MS method is used in explosives investigation, drug detection, fire investigation, environmental analysis, and identification of unknown samples [18-20].

Here, we disclose a clean and mild procedure for the protection of alcohols and phenols using HMDS in the presence of $\mathrm{LaCoO}_{3}$ under green solvent-free conditions with good to excellent yields (Scheme 1).

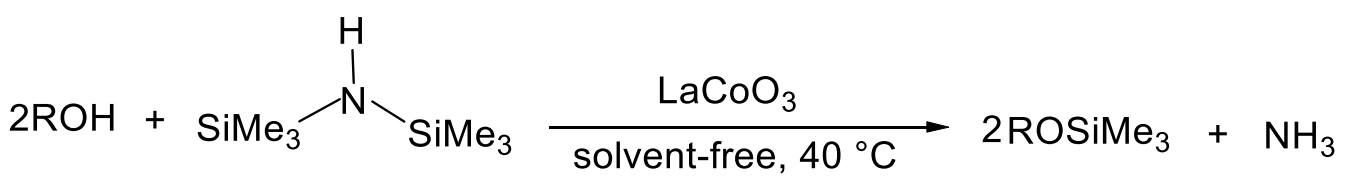

Scheme 1. Trimethylsilylation of alcohols and phenols with HMDS catalyzed by $\mathrm{LaCoO}_{3}$

\section{Experimental}

\section{General}

All chemicals were purchased from Fluka, Merck, or Aldrich chemical companies. The $\mathrm{LaCoO}_{3}$ catalyst was prepared as reported previously [14]. The used domestic microwave oven was LG-30L, 900W, MW frequency 2.45GHz. GC-Mass measurement was recorded using a Shimadzu GCMS-QP 505 A with DB5 column. Helium gas with the purity of $99.999 \%$ was used as

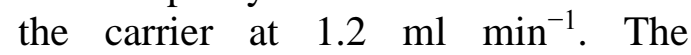
software used for the data acquirement and processing was Lab solution. The temperatures of injector and interface were maintained at $250{ }^{\circ} \mathrm{C}$ and $280{ }^{\circ} \mathrm{C}$, respectively. The temperature program for the column oven was as follows: 70 ${ }^{\circ} \mathrm{C}$ for $2 \mathrm{~min}$, a linear ramp to $250{ }^{\circ} \mathrm{C}$ at $10{ }^{\circ} \mathrm{C} / \mathrm{min}$ and a $5 \mathrm{~min}$ held. The electron impact (EI)-ionization was performed at $70 \mathrm{eV}$.

\section{Preparation of $\mathrm{LaCoO}_{3}$ perovskite}

To prepare $\mathrm{LaCoO}_{3}$ perovskite, $\mathrm{La}\left[\mathrm{Co}(\mathrm{CN})_{6}\right] .5 \mathrm{H}_{2} \mathrm{O}$ powder was pressed into pellets with a pressure of $200 \mathrm{MPa}$ and was put in a porcelain crucible. The crucible was placed in another larger porcelain crucible in the presence of $\mathrm{CuO}$ powder. This assembly was placed in a microwave oven and irradiated at the highest power level of $900 \mathrm{~W}$ in the air for $10 \mathrm{~min}$. After this time, the $\mathrm{CuO}$ powder became fully red hot, the complete decomposition of the precursor pellet occurred. The product was cooled to room temperature and collected for catalytic applications [14].

Trimethylsilylation of alcohols and phenols

A mixture of alcohol or phenol (10 mmol), $\mathrm{LaCoO} 3$ (0.01 g) and HMDS $(7.5 \mathrm{mmol})$ was prepared and stirred at $40{ }^{\circ} \mathrm{C}$ under solvent-free conditions for an appropriate time. The progress of the reaction was monitored by GC. After completion of the reaction, the $n$ hexane was added to the residual mixture and the catalyst was filtered. The evaporation of the solvent under reduced pressure afforded the silylated product.

\section{Results and discussion}


In the present work, we disclose a green and mild method for the protection of alcohols and phenols with HMDS using catalytic amounts of $\mathrm{LaCoO}_{3}$ under solvent-free heterogeneous reaction conditions at $40{ }^{\circ} \mathrm{C}$ with good to excellent yields. The organic solvent such as $\mathrm{CH}_{3} \mathrm{CN}$ and $\mathrm{CH}_{2} \mathrm{Cl}_{2}$ was not used. A solvent-free condition is more environmentally benign and economically feasible. In comparison to a reaction in organic solvents, the advantages of solvent-free condition include cost-effective, environmentally friendly and easy workup procedures, energy storage, and high yields.

At the beginning of this research, the protection of benzyl alcohol with HMDS as a model reaction in the presence of $\mathrm{LaCoO}_{3}$ as the catalyst was carried out to optimize the reaction conditions. After various experiments, $7.5 \mathrm{mmol}$ of HMDS (for $10 \mathrm{mmol}$ of the substrate) and $\mathrm{LaCoO}_{3}$ loading of $0.01 \mathrm{~g}$ at $40{ }^{\circ} \mathrm{C}$ under solvent-free conditions were selected as the optimized reaction conditions. In the absence of $\mathrm{LaCoO}_{3}$, only the small amounts of corresponding products were produced.

Encouraged by the obtained results, the various alcohols and phenols were applied for the synthesis of silyl ethers. The results have been shown in Table 1. Trimethylsilylation of primary alcohols proceeded efficiently with good to excellent yields (60-99\%). No elimination and rearrangement by-products were observed at all. Phenols also underwent silylation using this method to give silylation products in high yields (9899\%). Secondary alcohols were resistant to this method and gave low yeilds or no conversion under the selected conditions. Cyclohexanol was easily protected with HMDS in good yields despite being secondary alcohol, presumably because its cyclic $2^{\circ}$ alkyl group presents less steric hindrance than an acyclic $2^{\circ}$ alkyl group. The silylation of tertiary alcohols such as tert-butyl alcohol and triphenylmethanol did not occur.

Table 1. Trimethylsilylation of alcohols and phenols with $\mathrm{HMDS}$ catalyzed by $\mathrm{LaCoO}_{3}$ at $40{ }^{\circ} \mathrm{C}$

Entry




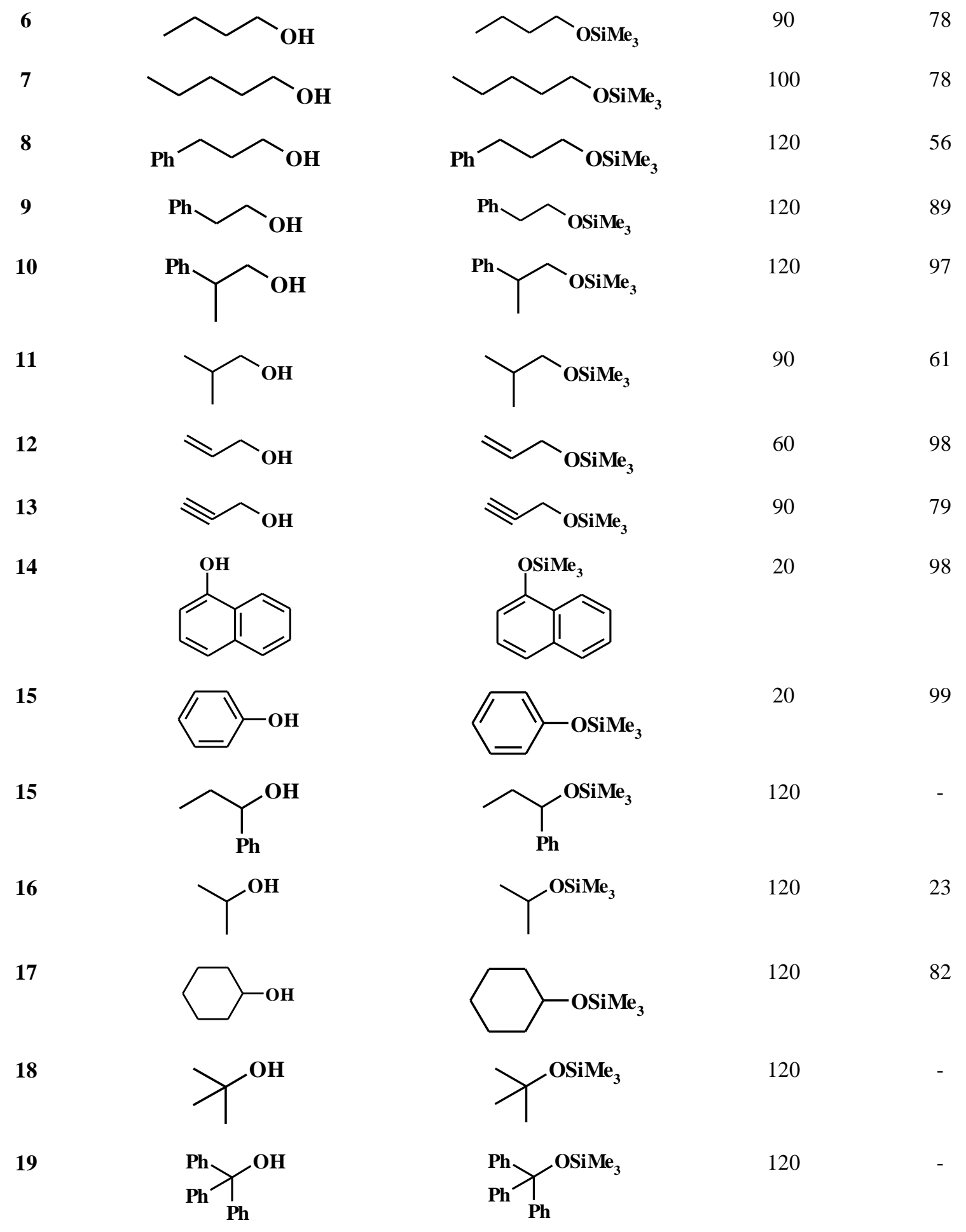

We also explored the ability of $\mathrm{LaCoO}_{3}$ and HMDS to discriminate between different kinds of hydroxy groups of alcohols and the selectivity is outlined in Scheme 2. The results showed that secondary alcohols are more reactive than tertiary alcohols, while, primary alcohols are more reactive than the secondary alcohols. It seems that the higher reactivity of primary alcohols in comparison with secondary and tertiary alcohols is due 
to their less steric hindrance for attacking to HMDS. Figure 1 shows the GC-Mass results in a binary mixture of benzyl alcohol and cyclohexanol, the benzyl alcohol was converted to the silyl ether product in $82 \%$ yield, while only $18 \%$ of the corresponding trimethylsilyl ether was observed for the cyclohexanol. A and $\mathrm{C}$ are related to the benzyloxy(trimethyl)silane and cyclohexyloxy(trimethyl)silane, respectively.
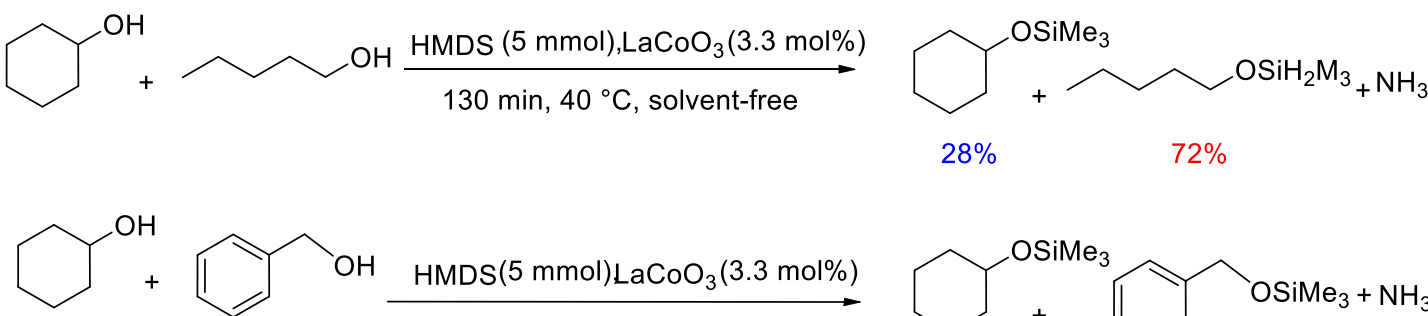

$\operatorname{HMDS}(5 \mathrm{mmol}) \mathrm{LaCoO}_{3}(3.3 \mathrm{~mol} \%)$<smiles>COCc1ccccc1COC(C)=[18O]</smiles>

$18 \%(C)$ $82 \%(\mathrm{~A})$<smiles>CC(C)(C)O</smiles><smiles>COC1CCCCC1</smiles>

$100 \%$

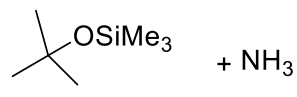

$0 \%$

Scheme 2. Comparison of reactivity of between hydroxy groups of alcohols (alcohol: $10 \mathrm{mmol}$ )

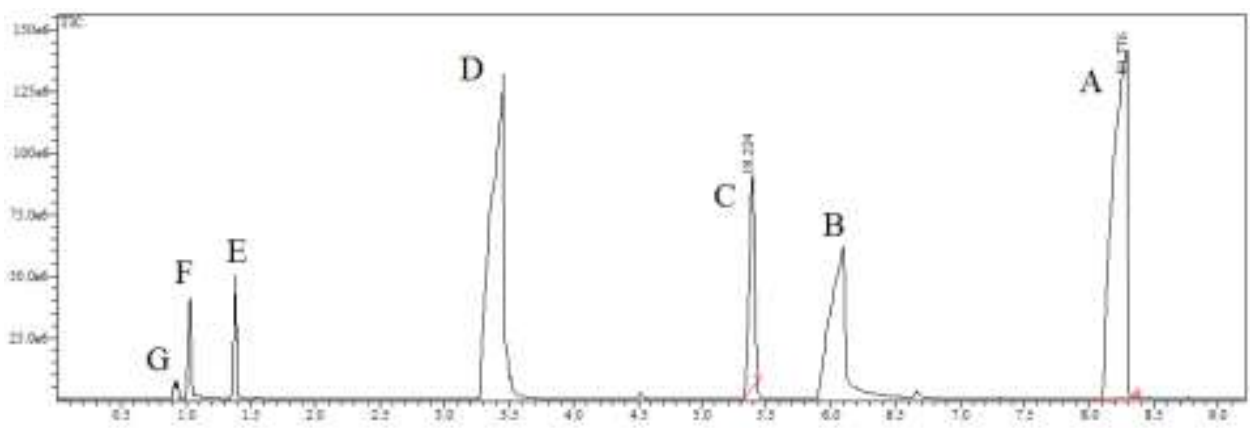

Figure 1. GC chromatogram related the mixture of reaction for trimethylsilylation of benzyl alcohol and cyclohexanol by the catalyst. A: benzyloxy(trimethyl)silane, B: benzyl alcohol, C: cyclohexyloxy(trimethyl)silane, D: cyclohexanol, E: impurity, F: impurity, and G: acetone

GC-Mass results for trimethylsilylation of $\alpha$-naphtol and mass spectrum of trimethyl(1naphthyloxy)silane are shown in Figure 2 . In the mass spectrum of trimethyl(1naphthyloxy)silane, the intense molecular ion peak is at $\mathrm{m} / \mathrm{z}=216$ and the intense peak at $m / z=201$ is due to loss of a methyl group.
A plausible mechanism for catalytic trimethylsilylation of alcohols by $\mathrm{LaCoO}_{3}$ is shown in Scheme 3. The $\mathrm{La}$ and Co cationic sites as Lewis acids polarizing the Si-N bonds in HMDS and converts it to a reactive silylating agent. Finally, the hydroxyl group of alcohols and phenols are silylated and ammonia gas is released as a byproduct [10]. 

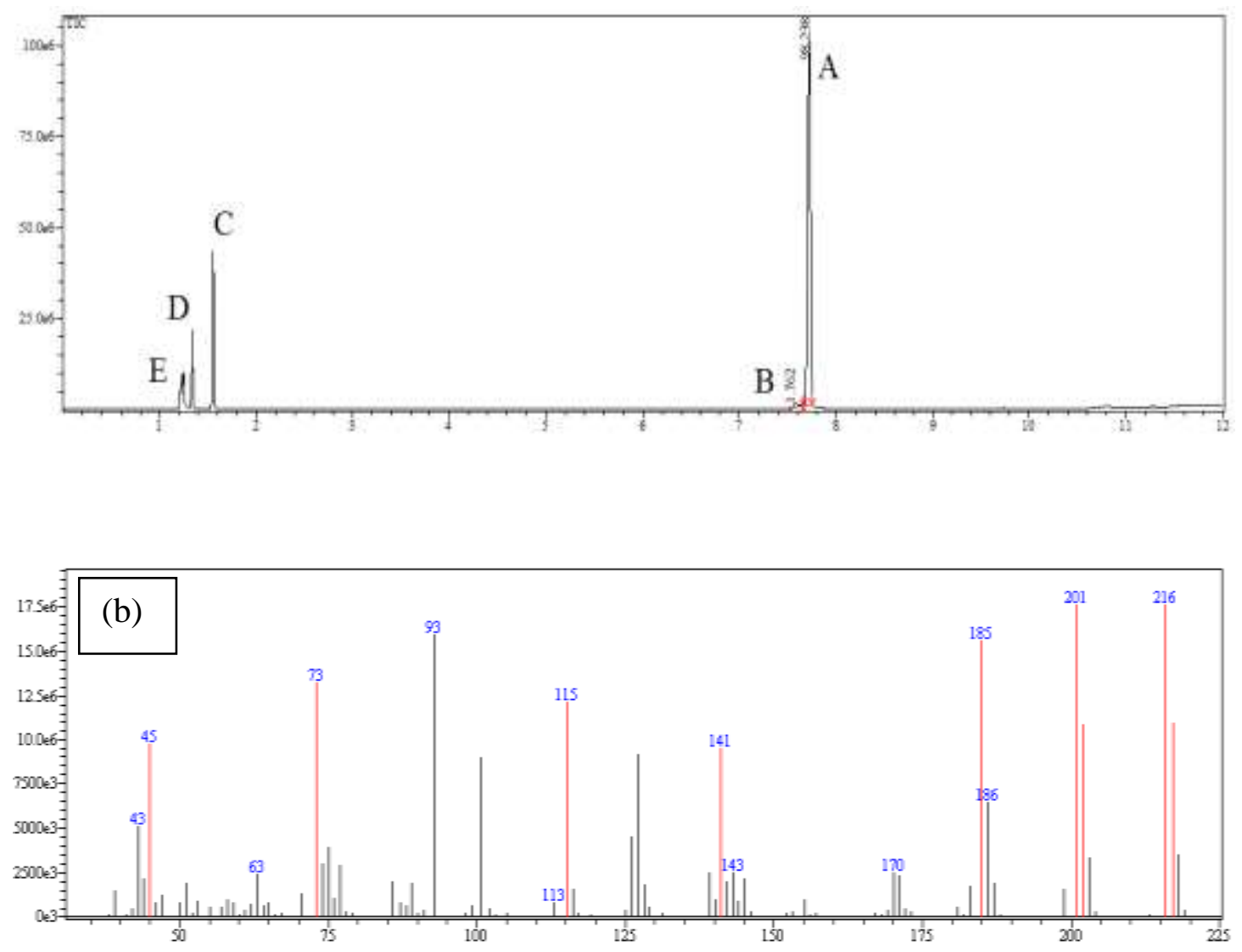

Figure 2. (a) GC chromatogram related the mixture of reaction for trimethylsilylation of $\alpha$-naphtol (A: trimethyl(1-naphthyloxy)silane, B: $\alpha$-naphtol, (C) HMDS, (D) impurity, and (E) acetone.) and (b) mass spectrum of trimethyl(1-naphthyloxy)silane

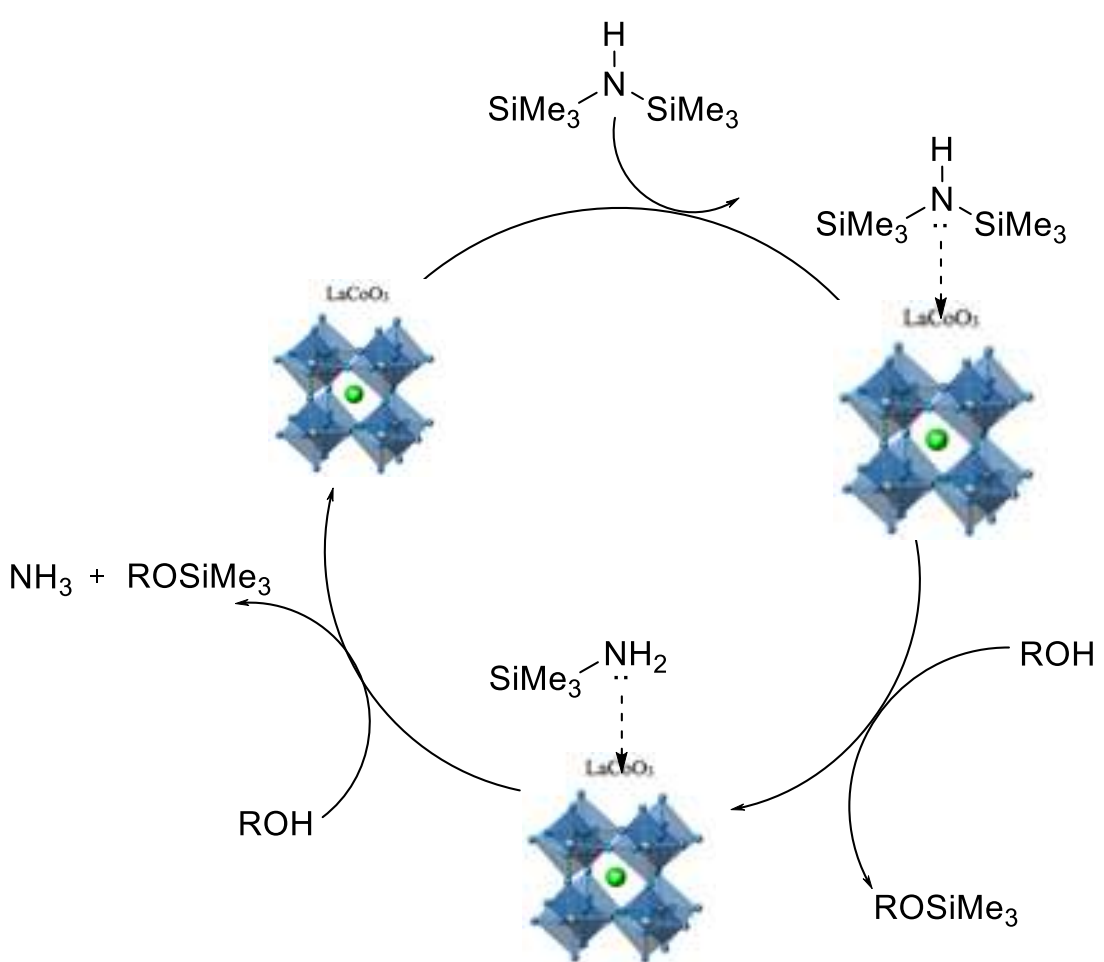


Scheme 3. Proposed mechanism for trimethylsilylation of alcohols with $\mathrm{HMDS}$ catalyzed by $\mathrm{LaCoO}_{3}$

The catalytic role of $\mathrm{LaCoO}_{3}$ for the trimethylsilylation of $\alpha$-naphtol has been compared with previously reported catalysts and the results are summarized in Table 2. This catalytic method offers several advantages, in comparison with other previously reported procedures, including highefficiency product, trace amounts of catalyst to the substrate, inexpensive and non-toxic catalyst, and easy and clean reaction process.

Table 2. Comparison of the activity of various catalysts in the silylation of $\alpha$-naphtol with HMDS

\begin{tabular}{|c|c|c|c|c|c|}
\hline Entry & Catalyst & Condition & Time (min) & Yeild (\%) & Ref. \\
\hline 1 & $\mathrm{LiClO}_{4}-\mathrm{SiO}_{2}$ & $\mathrm{CH}_{2} \mathrm{Cl}_{2}, \mathrm{RT}$ & 120 & 90 & 21 \\
\hline 2 & MMT-K10 & $\mathrm{CH}_{2} \mathrm{Cl}_{2}, \mathrm{RT}$ & - & 92 & 22 \\
\hline 3 & $\mathrm{I}_{2}$ & $\mathrm{CH}_{2} \mathrm{Cl}_{2}, \mathrm{RT}$ & - & - & 7 \\
\hline 4 & NBS & $\mathrm{CH}_{2} \mathrm{Cl}_{2}, \mathrm{RT}$ & 180 & 93 & 8 \\
\hline 5 & $\mathrm{CuSO}_{4} .5 \mathrm{H}_{2} \mathrm{O}$ & $\mathrm{CH}_{3} \mathrm{CN}$, reflux & $38 \mathrm{~h}$ & 50 & 9 \\
\hline 6 & $\mathrm{KBr}$ & $\mathrm{CH}_{3} \mathrm{CN}, \mathrm{RT}$ & $7-8$ & 85 & 23 \\
\hline 7 & $\mathrm{Si}\left(\mathrm{CH}_{3}\right)_{3} \mathrm{Cl}$ & Solvent-free, $125^{\circ} \mathrm{C}$ & - & - & 24 \\
\hline 8 & $\mathrm{LaCoO}_{3}$ & Solvent-free, $40^{\circ} \mathrm{C}$ & 20 & 98 & This work \\
\hline
\end{tabular}

\section{Conclusion}

We have reported a new catalytic protocol for the efficient and selective trimethylsilylation of alcohol and phenols in the presence of $\mathrm{LaCoO}_{3}$ under solvent-free and ambient conditions. This clean methodology offers non-toxic conditions, high selectivity, cost-effective reagents and catalyst, and an easy workup.

\section{Acknowledgments}

We are grateful to the Lorestan University Research Council for partial support of this work.

\section{References}

[1] A. Ghorbani-Choghamarani, N. Cheraghi-Fathabad, Chin. J. Catal., 2010, 31, 1103-1106.
[2] A. Ghorbani-Choghamarani, M.A., Zolfigol, M. Hajjami, S. Jafari, J Chin Chem Soc., 2008, 55, 1208-1213.

[3] F. Shirini, M. Abedini, J. Iran. Chem. Soc., 2008, 5, S87-S90.

[4] A. Biffis, E. Castello, M. Zecca, M. Basato, Tetrahedron, 2001, 57, 1039110394.

[5] T. Shibata, K. Kanda, Y. Ueno, R. Fujiwara, Bull Chem Soc Jpn., 2006, 79, 1146-1147.

[6] D. Zareyee, B. Karimi, Tetrahedron Lett., 2007, 48, 1277-1280.

[7] B. Karimi, B. Golshani, J. Org. Chem., 2000, 65, 7228-7230.

[8] A. Khazaei, A. Rostami, A. Raiatzadeh, M. Mahboubifar, Can. J. Chem., 2007, 85, 336-340.

[9] B. Akhlaghinia, S. Tavakoli, Synthesis, 2005, 1775-1778. 
[10] A. Azad, M.G. Dekamin, S. Afshar, A. Tadjarodi A., Mollahosseini, Res. Chem. Intermediat., 2018, 44, 2951-2963.

[11] F. Shirini, M.A. Zolfigol, M. Abedini, Bull Chem Soc Jpn., 2005, 78, 1982-1985.

[12] M. Moghadam, S Tangestaninejad, V. Mirkhani, I. Mohammadpoor-Baltork, S. Gharaati, Polyhedron, 2010, 29, 212-219.

[13] M. Ao, G.H. Pham, V. Sage, V. Pareek, J. Mol. Catal. A: Chem., 2016, 416, 96-104.

[14] S. Farhadi, S. Sepahvand, J. Alloys Compd., 2010, 489, 586-591.

[15] P.H.T. Ngamou, K. KohseHöinghaus, N. Bahlawane, Catal. Commun., 2011, 12 (14), 1344-1350. [16] X. Yang, L. Yang, W. Fan, H. Lin, Catal. Today., 2016, 269, 56-64.

[17] Y. Yamada, K. Yano, D. Honga, S. Fukuzumi, Phys. Chem. Chem. Phys., 2012, 14, 5753-5760.
[18] (a) H. Saeidian, D. Ashrafi, M. Sarabadani, M.T. Naseri, M. Babri, Int. J. Mass Spectrom., 2012, 319-320, 916; (b) Z. Arzehgar, S. Sajjadifar, H. Arandiyan, Asian J. Green Chem., 2019, 3, 43-52.

[19] H. Saeidian, M. Babri, D. Ashrafi, M. Sarabadani, M.T. Naseri, Anal. Bioanal. Chem., 2013, 405, 6749-6759. [20] M.T. Naseri, M. Sarabadani, D. Ashrafi, H. Saeidian, M. Babri, Environ. Sci. Pollution Res., 2013, 20, 907-916.

[21] N. Azizi, R. Yousefi, M.R. Saidi, J. Organomet. Chem., 2006, 691, 817820.

[22] (a) Z.H. Zhang, T.S. Li, F. Yang, C.G. Fu, Synth. Commun., 1998, 28, 3105-3114; (b) S. Sajjadifar, Chemical Methodologies, 2017, 1, 1-11; (c) M. Asif, J. Chem. Rev., 2019, 1, 66-77.

[23] F. Shirini, M. Esmail, Synth Commun., 2006, 36, 1109-1115.

[24] S.H. Langer, S. Connell, I. Wender, J. Org. Chem., 1958, 23, 5058.

How to cite this manuscript: Ebrahim Mehdipour, Ehsan Baharlouei, Zohre Zarnegar. "Selective trimethylsilylation of alcohols and phenols with hexamethyldisilazane catalyzed by $\mathrm{LaCoO}_{3}$ perovskite". Eurasian Chemical Communications, 2019, 433-440. 